\title{
Hospital Waste Management in Ondo State South West Nigeria
}

\author{
Josephine Omowumi Olayinka-Olagunju", Caleb Akinyemi
}

Department of Environmental Biology and Fisheries, Adekunle Ajasin University, Nigeria

Copyright (C) 2015 by authors, all rights reserved. Authors agree that this article remains permanently open access under the terms of the Creative Commons Attribution License 4.0 International License

\begin{abstract}
This study investigates the waste management practices in some selected hospitals in the densely populated regions of Ondo state. Five (3 public and 2 privates) hospitals were assessed, wards ranges from 2 to 10 and number of beds ranges from 12 to 84 . The study shows complete absence of medical waste tracking, monitoring and testing programme in all the hospitals. In addition, institutionalized medical waste management plan were also absent from all the hospitals, only one had an abatement facility in form of mini-incinerator. However, open dump sites were seen within some of the hospital premises. Medical waste generation rates ranged between $0.38 \mathrm{~kg} / \mathrm{bed} /$ day and $0.97 \mathrm{~kg} / \mathrm{bed} /$ day to $0.7 \mathrm{~kg} / \mathrm{bed} / \mathrm{ward} /$ day and $4.38 \mathrm{~kg} / \mathrm{bed} / \mathrm{ward} /$ day, while on average, a generation rate of $0.676 \mathrm{~kg} / \mathrm{bed} /$ day and $2.51 \mathrm{~kg} / \mathrm{bed} / \mathrm{ward} /$ day were obtained. More so, it was also observed that numerous kinds of wastes generated were not separated into different bins but disposed in the same refuse bins. The most predominant methods of waste treatments practiced at the hospitals were burning and deep burial. All hospitals and other medical institutions in the state engage the services of the state government waste disposal board for their final collection and disposal of waste as there are no private waste contractors in the state.
\end{abstract}

Keywords Medical Waste, Disposal Bin, Deep Burial, Incinerator, Open Dump, Ward, Waste Management

\section{Introduction}

Municipal solid waste (MSW) generation is fast becoming a major challenge across the globe. The current global municipal solid waste generation is approximately estimated at 1.3 billion tonnes per year and the figure is expected to double by 2050 to approximately 2.2 billion tonnes per year $[1,2]$. In a bid to curb the increasing rate of MSW, implementation of waste minimization programme was made [3]. [4] have argued that the problems of co-disposal of municipal solid waste such as hospital waste with pathogenic and infectious materials; commercial wastes e.g. used oil, batteries and paints; inorganic industrial wastes like acids, heavy metals, and asbestos; and organic industrial wastes like solvents, pesticides, have particular hazards on the waste pickers (scavengers) and people living within the dump site areas. According to the New York State Health Department [5], hazardous waste is defined as all substances that are hazardous to human health and the environment. In spite of the serious impacts of medical waste on human and the environment, only little attention has been directed to its proper handling and disposal. Medical waste include materials that are produced in the course of health protection, medical treatment and scientific research which forms a separate category medical or health care waste [6][7].

In Nigeria, the Federal Environmental Protection Agency (FEPA) has classified health care waste as infectious waste which include, culture and stock of infectious agents, pathological waste, waste from surgery or autopsy that were in contact with infectious agents, sharps (hypodermic needles, syringes, scalpel blades), waste from human blood and products of blood and laboratory waste [8]. Furthermore, WHO [9] defines Health Care Waste (HCW) as the total waste stream from a healthcare or research facility that includes both potential risk waste and non-risk waste materials. Medical establishment such as hospitals, medical institutes and laboratory are among the largest creation of MSW on a per capita basis. World Health Organization [10] revealed that the aim of health-care establishment to its worker, patients and the public is to make medical waste management safe and sustainable.

Medical wastes therefore constitute a larger portion of infectious wastes, which are potentially dangerous because they may contain pathogenic agents. The production of these wastes will also continue to be an on-going phenomenon as long as there are human activities [11]. However, health-care waste can result in serious harm if not managed correctly. Improper waste management can cause environmental pollution, unpleasant odours, and growth of insects, rodents and worms; it may lead to transmission of diseases like 
typhoid, cholera, and hepatitis through injuries from sharps contaminated with human blood [11]

According to PATH [12], it has been observed that every year unsafe injections and needle stick injuries cause at least: 8-16 million hepatitis $\mathrm{B}$ infections, 2.3-4.7 million hepatitis $\mathrm{C}$ infections, and 160,000 HIV/AIDS infections among health care workers, waste pickers and handlers, drug addicts. In addition, health-care activities generate significant amounts of hazardous waste such as mercury and expired pharmaceuticals, as well as large amounts of general waste [9]. The objective of this study is to investigates the waste management practices (techniques employed and disposal methods) in five selected hospitals in the densely populated regions of Ondo state, South West Nigeria

\section{Materials and Methods}

\subsection{Study Area}

This study was conducted in Ondo State, South West geopolitical zone in Nigeria. The state covers an area of $15,195.2$ square kilometers and a latitude of $7^{0} 10$ " north and longitude of $5^{0} 05^{\prime}$ East. The map of the state is shown in Figure 1 below. It occupies an area of 14, 788.723 square kilometres with estimated population of 3,460,877 [13] and a population density of 218 people per sq. $\mathrm{km}$. The state accounts for $2.5 \%$ the country's population. The temperature throughout the year ranges from $21^{\circ} \mathrm{C}$ to $30^{\circ} \mathrm{C}$ with humidity relatively high. The annual rainfall varies from $2,000 \mathrm{~mm}$ in the southern parts to $1,150 \mathrm{~mm}$ in the northern areas. The rainfall decreases in amount and distribution from the cost to hinterland. Figure 1 show the map of Ondo State and its various local government areas [14].

\subsection{Methodology}

Feasibility study for each hospital was carried out before the research was conducted. Five different hospitals were selected for this study; 2 privates and 3 public. These hospitals are located in different local government area of the state. Table 1 shows the statistics of the hospitals used during this study.

\subsection{Data Collection}

Data were collected using three instrument namely; questionnaire administration, in depth interview and observation strategy /discussion. Study commenced with the current state of waste management to recycling and disposal activities in each hospital. Information on each hospital was confirmed from the directors of the hospital by interviews. Furthermore, the use of structured questionnaires, one on one discussions and participant observed strategy was employed. This study lasted for 6 months July to December 2013. The questionnaires were simple and objective based on the guidelines of the safe management of waste from health care facilities were self-administered and interviews were conducted among officers in charge of medical waste in each hospital. Health care managers, nurses, nursing assistants and waste handlers within and outside the hospitals were among those interviewed. The questionnaires contained information on medical waste generation, segregation, collection, storage, transportation, treatment and final disposal.

\subsection{Ethnic Consideration}

Permission was obtained from Ondo State Hospital Board Management Akure, Ondo State and also each hospital before conducting the research.

Table 1. Statistics of the Surveyed Hospitals

\begin{tabular}{|c|c|c|c|}
\hline Hospitals & \multicolumn{1}{|c|}{ Location } & Types & Number of Wards \\
\hline A & $\begin{array}{c}\text { Located in a medium to high densely populated area of } \\
\text { Ikare of the metropolis. The treat both general and few } \\
\text { specialized case }\end{array}$ & Public & 10 \\
\hline B & $\begin{array}{c}\text { It is located in the low to medium densely populated } \\
\text { area of the state, Iwaro-Oka. It treats general cases. }\end{array}$ & Public & 5 \\
\hline C & $\begin{array}{l}\text { It is located in the low to medium densely populated } \\
\text { area of the state, Iwaro-Oka. It treats general cases. }\end{array}$ & Public & 28 \\
\hline D & $\begin{array}{c}\text { A specialist hospital located in medium to high densely } \\
\text { populated area of the state capital in Akure. It treats } \\
\text { both general and specialized cases. }\end{array}$ & Private & 6 \\
\hline E & $\begin{array}{c}\text { Located in medium to high densely populated great of } \\
\text { the state capital in Akure. It treats general cases. }\end{array}$ & Private & 27 \\
\hline
\end{tabular}




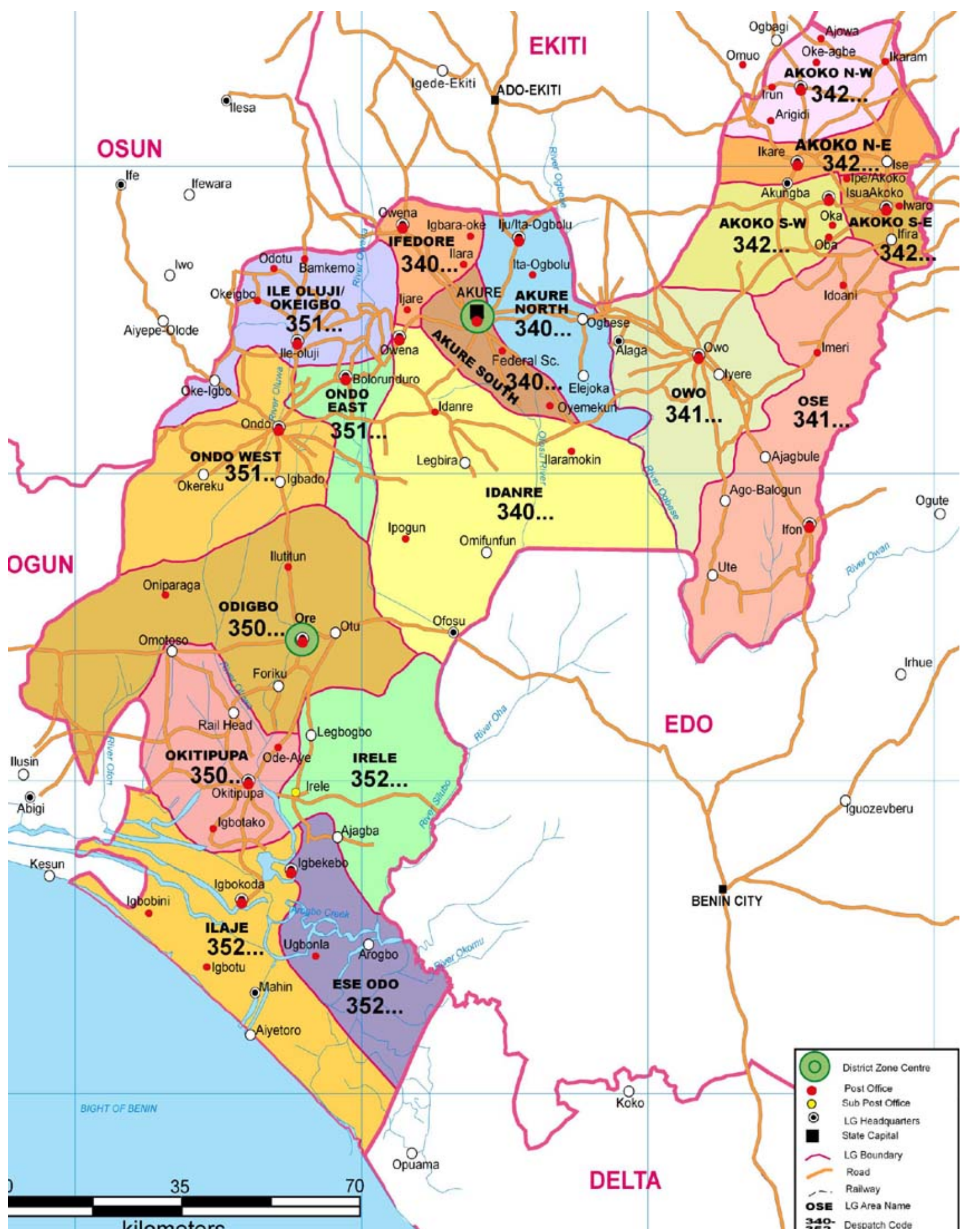

Figure 1. Map of Ondo State (http://nigeriazipcodes.com/ Assessed 15/09/2015 [15]) 


\subsection{Results}

\subsubsection{Statistics of Hospitals}

Table 2 shows the characterization of waste in the hospitals while table 3 shows the waste management practices used each hospital. The hospitals were measured with three principal criteria as stipulated in the National Guidelines for the presence or absence of a tracking programme, monitoring and testing and the existence of any Medical Waste Management Plan (MWMP) in place.

Medical waste generation in each hospital ( $\mathrm{kg} / \mathrm{bed}$ day and total waste generated in $\mathrm{kg} /$ day) is shown on Table 4 . Medical waste generation ranged between $0.38 \mathrm{~kg} / \mathrm{bed} / \mathrm{day}$ and $0.97 \mathrm{~kg} / \mathrm{bed} / \mathrm{day}$ to $0.7 \mathrm{~kg} / \mathrm{bed} / \mathrm{ward} / \mathrm{day}$ and 4.38 $\mathrm{kg} / \mathrm{bed} / \mathrm{ward} / \mathrm{day}$, while on average, a generation rate of $0.676 \mathrm{~kg} / \mathrm{bed} /$ day and $2.51 \mathrm{~kg} / \mathrm{bed} / \mathrm{ward} /$ day were obtained.

\subsubsection{Internal Medical Waste Collection and Storage}

In the studied hospitals, the cleaners and nursing assistance are responsible for the collection of medical waste from the wards to the various storage centres in all the hospitals. Collections of medical waste from the wards to the deposal centres are done mostly three times daily. The staff were seen pouring the waste in the different coloured bags and carrying the waste to the hospital general disposal bin within the hospital where it is later collected by the waste management board. The frequency of waste collection from internal storage facilities by external waste collectors is irregular. Many of the cleaners confirmed that general collection by Waste Management Board could be once or twice a week in private hospital while in public hospitals it is sometime collected once in a month or even once in more than a month. Summary of waste collection frequency is shown on Table 5.

Table 2. Solid waste Composition from the studied hospitals

\begin{tabular}{|l|l|}
\hline \multicolumn{1}{|c|}{ Waste Types } & \multicolumn{1}{c|}{ Description } \\
\hline Domestic & $\begin{array}{l}\text { Food leftovers used toiletry, food cans and used } \\
\text { papers. }\end{array}$ \\
\hline Glass & $\begin{array}{l}\text { Pasteur pipettes and broken glasses, disposable } \\
\text { culture dishes, specimen containers. }\end{array}$ \\
\hline Sharps & Disposable needles \& syringes, scalpel blades \\
\hline $\begin{array}{l}\text { Surgery and } \\
\text { Autopsy waste }\end{array}$ & $\begin{array}{l}\text { Soiled dressings, sponges, drapes, lavage } \\
\text { tubes, drainage sets, sanitary pads and surgical } \\
\text { gloves. }\end{array}$ \\
\hline $\begin{array}{l}\text { Pharmaceutical } \\
\text { wastes }\end{array}$ & $\begin{array}{l}\text { Expired drugs and chemicals or contaminated } \\
\text { drugs. }\end{array}$ \\
\hline Dialysis unit wastes & $\begin{array}{l}\text { Tubing, filters, disposable sheet, towels, gloves } \\
\text { and laboratory coats. }\end{array}$ \\
\hline $\begin{array}{l}\text { Contaminated } \\
\text { equipment }\end{array}$ & $\begin{array}{l}\text { Equipment used in patient care, medical } \\
\text { laboratories and research }\end{array}$ \\
\hline $\begin{array}{l}\text { Microbiological } \\
\text { waste }\end{array}$ & $\begin{array}{l}\text { Specimen containers, slides and cover slips, } \\
\text { disposable gloves, lab coats and aprons. } \\
\text { Cultures, stocks of infectious agents from clinic } \\
\text { research }\end{array}$ \\
\hline
\end{tabular}

\subsubsection{Waste Treatments and Disposal Methods}

The most prevailing method of waste treatments practiced at the hospitals were burning and deep burial of medical waste. It was also observed that no medical infectious waste was excluded from these practices. In addition, another common practice noted at some of the hospitals was the disposal of infectious and regulated waste types seen on open land within the hospital premises and canal very close by. This kind of practice is a very poor medical waste management practices which usually pose as risk to public health within and outside the hospitals. Only one of the private hospital visited had a mini-incinerator used for disinfecting used needles and it is the most outstanding out of the five. None of the hospital engaged the service of environmental officers to oversee their treatment and disposal of its medical waste. More so, hospitals employ the services of public waste collectors for their waste collection and final disposal to government authorized dumps.

Table 3. Medical Waste Management consideration

\begin{tabular}{|c|c|c|c|c|}
\hline Hospital & $\begin{array}{c}\text { Tracking } \\
\text { program }\end{array}$ & $\begin{array}{c}\text { Monitoring } \\
\text { \& Testing }\end{array}$ & $\begin{array}{c}\text { Abasement } \\
\text { facility }\end{array}$ & MWMP \\
\hline A & Absent & Absent & None & Absent \\
\hline B & Absent & Absent & None & Absent \\
\hline C & Absent & Absent & None & Absent \\
\hline D & Absent & Absent & $\begin{array}{c}\text { Mini- } \\
\text { incinerator }\end{array}$ & Absent \\
\hline E & Absent & Absent & None & Absent \\
\hline
\end{tabular}

*MWMP: Medical Waste Management Plan

\subsection{Equation}

\subsubsection{Equation Format}

Waste Generation rate $\mathrm{kg} / \mathrm{bed} / \mathrm{day}=\frac{\text { Total no of bed }}{\text { Total waste generated }}$

Table 4. Medical Waste Generation in Surveyed Hospitals

\begin{tabular}{|c|c|c|c|}
\hline Hospital & $\begin{array}{c}\text { Total waste } \\
\text { generated }\end{array}$ & $\begin{array}{c}\text { Generation rate } \\
\mathbf{k g} / \mathbf{b e d} / \mathbf{d a y}\end{array}$ & $\begin{array}{c}\text { Generation } \\
\text { rate kg/ward/day }\end{array}$ \\
\hline $\mathrm{A}$ & 54.0 & 0.64 & 1.80 \\
\hline $\mathrm{B}$ & 10.5 & 0.38 & 0.70 \\
\hline $\mathrm{C}$ & 15.3 & 0.96 & 3.80 \\
\hline $\mathrm{D}$ & 26.3 & 0.97 & 4.38 \\
\hline $\mathrm{E}$ & 5.6 & 0.47 & 1.87 \\
\hline Total & 111.7 & 0.68 & 2.51 \\
\hline
\end{tabular}

Table 5. Frequency of Waste Disposal in the different Hospitals

\begin{tabular}{|c|c|c|}
\hline Hospital & Frequency of disposal & $\begin{array}{c}\text { Frequency of } \\
\text { collection per day }\end{array}$ \\
\hline A & Twice in a month & Three \\
\hline B & Once in a month & Three \\
\hline C & Not Specific & Three \\
\hline D & $\begin{array}{c}\text { Twice in a week (Monday \& } \\
\text { Tuesday) }\end{array}$ & Three \\
\hline E & Once a week (Tuesday) & Three \\
\hline
\end{tabular}

\subsection{Discussion}


Waste management practices in each hospital as revealed in this study shows complete absence of medical waste tracking, monitoring and testing programme in all the hospitals. More so, institutionalized medical waste management plan were also absent in any of the hospital. From the observation regulated domestic waste constitutes more than $50 \%$ of the total medical waste stream. More so, it was observed from this study that none of the hospitals keep the records of waste generated either as volume of weight. Waste can be measured in two ways; volume and weight. However, weight has advantages over volume because of it consistency and accuracy. [15] studied the volume and weight and they reported that weight is effective and cheaper in pricing than the volume from composted waste and other non-recyclable waste.

In addition, it was observed that dump sites are located within some of the hospital premises. Since the hospitals had no waste data, many of the bins were therefore weighted and generated data were recorded and evaluated. This may not be accepted as an absolute value for the entire metropolis due to existence of multiplicity of healthcare facilities within mega city. The total volume of medical waste generated in all the hospitals was $111.7 \mathrm{~kg} /$ day. This translates to $2.73 \mathrm{~kg} / \mathrm{bed}$ month and calculated total waste volume of $3,351 \mathrm{~kg} / \mathrm{month}$ by all hospitals. Because of the poor policy on medical generation in the state it was difficult to get the volume of infectious waste, sharp and chemical waste. This result is similar to the ones obtained by $[16,3]$. More so, the result shows that the hospital visited do not follow the guidelines on health care waste management as shown by [17]

The study also revealed poor handling of waste by the workers an act very dangerous for health staff dealing with waste because they are exposed to high occupational and health hazards. The most important steps in reducing the volume of hazardous/infectious waste from other municipal solid waste is by waste minimization and segregation [17]. This method will enable each hospital to know the volume of waste generated and it will make assessment more accurate. In addition, the separation method should be accompanied by the use of labelled or coloured bin bags and boxes for collecting sharps. [18] revealed that separation of hazardous/infectious waste from other kind of waste is the right step to reducing health risk.

Although the public hospitals visited employed the use of colour coding bin system which is in contrast to the private ones, but the method is poorly handled. The coloured bins and how they are used are; green disposal bins for collection of sanitary pad; red bins for collection of sharps; blue bins for collection of blood stained cottons, gauze and bandage. Thus it was observed that some hospitals had the coloured code system bins but do not follow it uses accordingly. In one of the hospital, sharps (e.g. needles) were seen stored in medical waste boxes prior to treatment and before final disposal.

One of the barriers to medical waste coding system in State is that there is no uniformity in the hospitals colour coding system. This is similar to [18] that the existing national Guideline is silent about it this important aspect of the MSWM. Waste collection frequency days should be reviewed, because generated medical waste in various hospital were left for days even weeks around the hospital premises. These poor practices should be looked into not only by the hospital staff but also the Ministries of Environment and Health. However, these unpleasant practices are common with the public hospitals. This could be as a result of the numbers of patients that visits the government (public) hospitals and also because many of the hospitals are less funded by the government such that the hospital management needs to generate fund to run the hospitals. In contrast, the private hospitals stood out because they employ the service of Government Waste Authorities adequately, pay as you throw (PAYT). But in the public hospitals, one of the areas visited was still waiting for the waste authorities to come collect the waste expect the government to pay since they themselves are owned by Government.

In conclusion, this research has revealed some of the dangers associated with medical or healthcare waste in our hospital and environment at large, it therefore necessary that the authorities in charge of should enforce the healthcare waste management plan so that the society can be free from risk associated with medical waste and our environment can be a sustainable place for all.

\section{Conclusions and Recommendations}

Licensed private waste collectors services should be encouraged and employed in the state. This will solve the problem of waste collection and the frequency of in hospitals will be improved. There should be adequate legal backing and sanction in the case of non-compliance by erring hospitals, health institutions and clinic of treatment dealing with infectious and sharps wastes. In addition, there should be availability of adequate monitoring facilities which can be used in the control of medical waste. Finally, medical waste handlers within health care facilities should be trained on methods and new techniques of handling medical and hazardous waste using WHO guidelines.

\section{REFERENCES}

[1] The World Bank. What a waste: A Global Review of Solid Waste Management, 2013 http:/go.worldbank.org/ Access $13^{\text {th }}$ September 2015.

[2] G. Gardner. Municipal solid waste growing. In the world watch institute, vital signs (20ed.) Washington, 2012.

[3] C. Visvanathan, J Tränkler,. Municipal Solid Waste Management in Asia- A Comparative Analysis, Workshop on Sustainable Landfill Management Chennai, India, pp. 3-15, 2003. 
[4] B. E. Bassey, M.O. Benka-Coker, H. S. A Aluyi. Characterization and management of solid medical wastes in the Federal Capital Territory, Abuja Nigeria. African Health Sciences 6(1): 58-632006

[5] New York State Department of Health, 1991. In: Axelrod, David (Ed.), Love Canal: A Special Report to the Government and Legislature. New York State Department of Health.

[6] D. Ropeik, G. Gray. Risk. Houghton Mifflin Company, New York (Boston), USA, 2002.

[7] K. Capak. Management of medical waste. In Proceedings of annual meeting of sanitary inspectors, pp. 117-124, 2001.

[8] K.A. Aderogba, A.A. Afelumo. Waste Dumps and their Management in Lagos Metropolis. International Journals of Learning and Development 2:1-16, 2012.

[9] World Health Organization. WHO Core principle for achieving safe and sustainable management of health-care waste 2007. Retrieved from http://www.who.int/water_sanitation_health/Environmental_ sanit/MHCWHanbook.htm

[10] World Health Organization. Health Care wastes, 1999. http://www.who.int/water_sanitation_health/Environmental sanit/MHCWHanbook.htm.

[11] E.B. Mehmet, S.B. Mehmet, E. Tugba. Medical waste management in Turkey: A case study of Istanbul. Waste Management (1); 445-448, 2009

[12] PATH. Proper Handling and Disposal of Auto-Disable Syringes and Safety Boxes Cover; A Training Module for Clinic Managers and Immunization Providers, 2006 http://www.path.org/vaccineresources/files/AD_and_Safety_ Box_Disposal.pdf Accessed 20th September 2015.

[13] National Population Commission, Nigeria. State Population, 2013 Accessed $23^{\text {rd }}$ August 2015. http://www.population.gov.ng/index.php/state-population

[14] Ondo State Diary. Produced by Ondo State Ministry of Information, 2012

[15] Nigeria Zip Codes. http://nigeriazipcodes.com/ Accessed $20^{\text {th }}$ August, 2015

[16] V. Linderhof, P. Kooreman, M. Allers, D. Wiersma Weight-based pricing in the collection of household waste: the Oostzaan case, Resource and Energy Economics, 23:359371,2001

[17] S.V. Manyele. Medical Waste Management in Tanzania: Current situation and the way forward. African Journals on Environmental Assessment Management. 8 (1): 74-99, 2004.

[18] E.O. Longe, A.Williams A preliminary study on medical waste management in Lagos Metropolis, Nigeria. Iranian Journal of Environmental Health Sciences and Engineering, 3(3), 1333-139, 2006. 